\title{
DIAGNÓSTICO QUANTITATIVO DA VEGETAÇÃO ARBÓREO- ARBUSTIVA DE DUAS PRAÇAS LOCALIZADAS NO BAIRRO JOSÉ E MARIA NO MUNICÍPIO DE PETROLINA-PE
}

\author{
QUANTITATIVE DIAGNOSIS OF THE ARBOREAL-SHRUB VEGETATION OF TWO \\ SQUARES LOCATED IN THE NEIGHBORHOOD JOSÉ AND MARIA IN THE \\ MUNICIPALITY OF PETROLINA-PE
}

Pedro Henrique Sousa Silva1 ${ }^{1}$, Danilo Diego de Souza²

\section{RESUMO}

Nas cidades existem muitos tipos de áreas verdes, como parques, jardins e praças que apresentam diferentes utilidades de acordo com sua função e estado de conservação. O objetivo deste trabalho foi realizar um diagnóstico quantitativo das espécies vegetais arbóreo-arbustivas que compõem a arborização das duas praças públicas do bairro José e Maria, em Petrolina-PE. O levantamento florístico quantitativo foi realizado pelo método enumeração total e as espécies foram identificadas e classificadas quanto à origem, nativas do Brasil e exóticas. $\mathrm{Na}$ análise das duas praças, os dados obtidos indicaram a presença de 161 indivíduos, pertencentes à 16 famílias botânicas e distribuídos em 25 espécies. O percentual de espécies exóticas foi de $n=102(63,35 \%)$ e as nativas brasileiras $n=59(36,65 \%)$. A espécie exótica que apresentou maior frequência foi Azadirachta indica, totalizando 38 indivíduos (23,6\%). A quantidade de espécies exóticas é superior em relação as nativas e esse fato pode ser explicado pela falta de planejamento da arborização urbana, em particular, nas praças públicas. O mais indicado é que o plantio de espécies nativas seja prioritário para evitar efeitos ambientais negativos e promover a conservação e valorização da flora da Caatinga.

Palavras-chave: Área verde urbana; Planejamento Urbano; Caatinga.

\begin{abstract}
In cities, there are many types of green areas, such as parks, gardens, and squares which have different uses according to their function and state of conservation. The objective of this study was to carry out a quantitative diagnosis of the arboreal-shrub plant species that make up the afforestation of the two public squares of José and Maria neighborhood, in Petrolina-PE. The quantitative floristic survey was performed by the total enumeration method and the species were identified and classified according to their origin, native to Brazil, and exotic. In the analysis of the two squares, data obtained indicated the presence of 161 individuals, distributed in 25 species, belonging to 16 botanical families. The percentage of exotic species was $n=102(63.35 \%)$ and the native Brazilian species $n=59(36.65 \%)$. The most common exotic species was Azadirachta indica, totaling 38 individuals (23.6\%). The number of exotic species is higher in relation to the native ones and this fact can be explained by the lack of urban afforestation planning for public squares. It is best indicated that the planting of native species is a priority to avoid negative environmental effects and the conservation and valorization of the Caatinga flora.
\end{abstract}

Keywords: Urban green area; Urban planning; Caatinga.

Recebido em 22.04.2020 e aceito em 23.07.2020

1 Biólogo. Especialista em Gestão e Educação Ambiental. Faculdade de Educação Superior de Pernambuco (FACESP).

Petrolina/PE. E-mail: phsousasilva@outlook.com

2 Biólogo. Mestre em Botânica. Agência Municipal de Meio Ambiente. Ouricuri/PE. E-mail: danilodiegos@hotmail.com 


\section{INTRODUÇÃO}

Nas últimas décadas houve um desalinhado crescimento de inúmeras cidades brasileiras e as ocupações irregulares têm agravado os planejamentos apropriados que possibilitem uma ligação entre a área construída com a área de vegetação. Pelas vantagens que a arborização urbana oferece, ela precisaria ser olhada como um dos elementos naturais mais relevantes que constituem o ecossistema das cidades e necessário em um planejamento urbano (OLIVEIRA et al., 2013).

A arborização urbana realiza várias funções no sistema de espaços livres da cidade, tendo como destaque a melhoria no microclima, a redução da poluição do ar, visual e sonora e abrigo para a fauna (BASSO; CORRÊA, 2014; PINHEIRO; SOUZA, 2017). Assim, estudos realizados nessas áreas são essenciais para indicar possibilidades de melhoria na quantidade $\mathrm{e}$ qualidade da vegetação, visando a qualidade ambiental das cidades.

Santos et al. (2011) afirmam que para ter um planejamento adequado é necessário inicialmente ser realizado um inventário que possibilite detectar problemas, caracterizar a riqueza arbórea do local, presumir futuras necessidades de manejo, como também apontar práticas fundamentais para a implantação correta de vegetação em cada ambiente urbano. Dessa forma, de acordo com Souza (2017), o monitoramento da vegetação para fins de planejamento é fundamental para o direcionamento de ações futuras, como escolha de espécies adequadas, implantação e manejo correto.

É necessário conhecer essas informações da arborização viária de uma cidade para que se consiga embasar ações de manutenção e manejo indispensáveis para a conservação das árvores. Esse conhecimento procede de um diagnóstico que depende da produção de um inventário florestal urbano (NOWAK, 2008). Por meio do inventário se torna possível conhecer as necessidades de manejo, detectar riscos referentes a árvores que precisem de melhorias ou até mesmo ser retirada, analisar as particularidades das ruas e elementos urbanos e designar novos pontos de plantio (BENATTI et al., 2012). Assim, o objetivo deste trabalho foi realizar um diagnóstico quantitativo das espécies arbóreo-arbustivas que compõem a arborização das duas praças públicas do bairro José e Maria, em Petrolina-PE, com intuito de conhecer a vegetação e identificar as necessidades de manejo. 


\section{MATERIAL E MÉTODOS}

\section{Área de estudo}

O estudo foi desenvolvido em duas praças públicas (Praça da Amizade e Praça Frei Damião), com cerca de 200 metros de distância entre elas, no bairro José e Maria, sendo esse, um dos maiores bairros e mais populosos de Petrolina-PE, com aproximadamente 127 hectares (Figura 1).

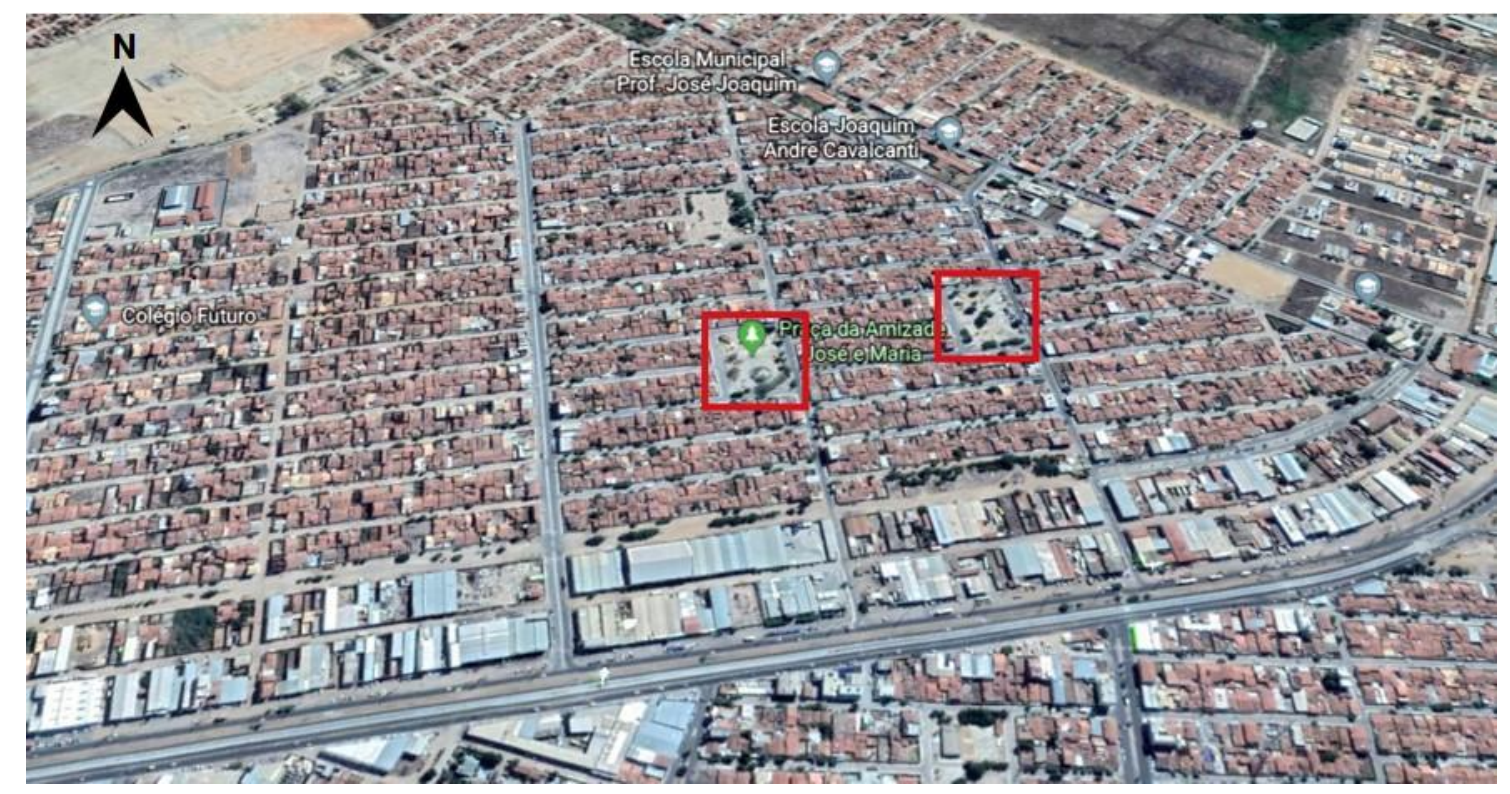

Fonte: Google Earth (2019)

Figura 1. Vista superior do bairro José e Maria e a localização das praças da Amizade (à esquerda) e Praça Frei Damião (à direita), Petrolina-PE

Figure 1. Top view of the José and Maria neighborhood and the location of Amizade (left) and Frei Damião (right) squares, Petrolina-PE

\section{Coleta e análise dos dados}

Para a análise dos dados florísticos quantitativos arbóreo-arbustivos foi utilizado o método enumeração total, no qual baseia-se na contagem de todos os indivíduos de interesse. Após a quantificação total dos indivíduos, obteve-se a frequência relativa de cada espécie, calculada pela razão entre o número de indivíduos da espécie e o seu número total, multiplicada por 100. As espécies também foram identificadas e classificadas quanto à origem (nativas do Brasil e exóticas), por meio de especialistas, consultas bibliográficas especializadas, além de pesquisa ao banco de dados de herbários virtuais, como o Herbário Vale do São Francisco (HVASF) e Herbário Virtual Reflora. 


\section{RESULTADOS E DISCUSSÃO}

Os dados obtidos quanto a composição florística da Praça da Amizade (Tabela 1) e Praça Frei Damião (Tabela 2) indicaram a existência de 161 indivíduos, distribuídos em 25 espécies, pertencentes à 16 famílias botânicas.

Tabela 1. Levantamento florístico arbóreo-arbustivo da Praça da Amizade, Petrolina-PE Table 1. Arboreal-shrub floristic survey of Amizade Square, Petrolina-PE

\begin{tabular}{|c|c|c|c|c|}
\hline \multicolumn{5}{|l|}{ PRAÇA DA AMIZADE } \\
\hline FAMÍLIA BOTÂNICA & \multirow{3}{*}{$\begin{array}{l}\text { NOME } \\
\text { POPULAR }\end{array}$} & \multirow{3}{*}{ ORIGEM } & \multirow[t]{3}{*}{ № } & \multirow{3}{*}{$\begin{array}{l}\text { FREQ } \\
\text { (\%) }\end{array}$} \\
\hline NOME CIENTÍFICO & & & & \\
\hline AGAVACEAE & & & & \\
\hline Agave americana L. & Agave & Exótica & 10 & 6,21 \\
\hline \multicolumn{5}{|l|}{ ANACARDIACEAE } \\
\hline Mangifera indica L. & Mangueira & Exótica & 04 & 2,49 \\
\hline Spondias purpurea L. & Seriguela & Exótica & 03 & 1,86 \\
\hline \multicolumn{5}{|l|}{ APOCYNACEAE } \\
\hline Nerium oleander $\mathrm{L}$. & Espirradeira & Exótica & 02 & 1,24 \\
\hline \multicolumn{5}{|l|}{ BIGNONIACEAE } \\
\hline Handroanthus sp. & Ipê & Nativa (Caatinga) & 01 & 0,62 \\
\hline Tabebuia aurea (Manso) Benth. \& Hook. f. ex S. & Caraibeira & Nativa (Caatinga) & 06 & 3,73 \\
\hline \multicolumn{5}{|l|}{ BORAGINACEAE } \\
\hline Cordia dichotoma G. Forst. & Pé-de-cola & Exótica & 03 & 1,86 \\
\hline \multicolumn{5}{|l|}{ CACTACEAE } \\
\hline Melocactus zehntneri (Britton \& Rose) Luetzelb. & Coroa-de-frade & Nativa (Caatinga) & 01 & 0,62 \\
\hline \multicolumn{5}{|l|}{ EUPHORBIACEAE } \\
\hline Jatropha gossypiifolia L. & Pinhão-roxo & Nativa (Caatinga) & 01 & 0,62 \\
\hline \multicolumn{5}{|l|}{ FABACEAE } \\
\hline Delonix regia (Bojer ex Hook.) Raf. & Flamboyant & Exótica & 03 & 1,86 \\
\hline Erythrina velutina Willd. & Mulungu & Nativa (Caatinga) & 01 & 0,62 \\
\hline Enterolobium contortisiliquum (Vell.) Morong. & Tamboril & Nativa (Caatinga) & 08 & 4,97 \\
\hline Prosopis juliflora (Sw.) DC. & Algarobeira & Exótica & 02 & 1,24 \\
\hline \multicolumn{5}{|l|}{ MALVACEAE } \\
\hline Hibiscus rosa-sinensis $\mathrm{L}$. & Hibisco & Exótica & 01 & 0,62 \\
\hline \multicolumn{5}{|l|}{ MELIACEAE } \\
\hline Azadirachta indica A. Juss & Neem & Exótica & 26 & 16,15 \\
\hline \multicolumn{5}{|l|}{ MORACEAE } \\
\hline Ficus benjamina $\mathrm{L}$. & Ficus & Exótica & 03 & 1,86 \\
\hline \multicolumn{5}{|l|}{ PUNICACEAE } \\
\hline Punica granatum $\mathrm{L}$. & Romãzeira & Exótica & 01 & 0,62 \\
\hline \multicolumn{5}{|l|}{ RHAMNACEAE } \\
\hline Ziziphus joazeiro Mart. & Juazeiro & Nativa (Caatinga) & 03 & 1,86 \\
\hline
\end{tabular}


Tabela 2. Levantamento florístico arbóreo-arbustivo da Praça Frei Damião, Petrolina-PE

Table 2. Arboreal-shrub floristic survey of Frei Damião Square, Petrolina-PE

\begin{tabular}{|c|c|c|c|c|}
\hline \multicolumn{5}{|c|}{ PRAÇA FREI DAMIÃO } \\
\hline FAMÍLIA BOTÂNICA & \multirow{3}{*}{$\begin{array}{c}\text { NOME } \\
\text { POPULAR }\end{array}$} & \multirow[t]{3}{*}{ ORIGEM } & \multirow{3}{*}{$\begin{array}{l}\text { QUANTI } \\
\text { DADE }\end{array}$} & \multirow[t]{2}{*}{ FREQ. (\%) } \\
\hline NOME CIENTÍFICO & & & & \\
\hline \multicolumn{2}{|l|}{ ANACARDIACEAE } & & & \\
\hline Mangifera indica L. & Mangueira & Exótica & 01 & 0,62 \\
\hline \multicolumn{5}{|l|}{ APOCYNACEAE } \\
\hline Nerium oleander L. & Espirradeira & Exótica & 14 & 8,7 \\
\hline \multicolumn{5}{|l|}{ ARECACEAE } \\
\hline Cocos nucifera L. & Coqueiro & Exótica & 01 & 0,62 \\
\hline Palmeira não identificada & Indeterminada & Exótica & 01 & 0,62 \\
\hline \multicolumn{5}{|l|}{ BIGNONIACEAE } \\
\hline Tabebuia aurea (Manso) Benth. \& Hook. f. ex S. & Caraibeira & Nativa (Caatinga) & 13 & 8,08 \\
\hline \multicolumn{5}{|l|}{ EUPHORBIACEAE } \\
\hline Jatropha gossypiifolia L. & Pinhão-roxo & Nativa (Caatinga) & 05 & 3,11 \\
\hline \multicolumn{5}{|l|}{ FABACEAE } \\
\hline Delonix regia (Bojer ex Hook.) Raf. & Flamboyant & Exótica & 04 & 2,49 \\
\hline Leucaena leucocephala (Lam) de Wit. & Leucena & Exótica & 01 & 0,62 \\
\hline Libidibia ferrea (Mart. ex Tul.) L.P. Queiroz & Pau-ferro & Nativa (Caatinga) & 13 & 8,08 \\
\hline Senna spectabilis (DC.) H.S.Irwin \& Barneby & Canafístula & Nativa (Caatinga) & 01 & 0,62 \\
\hline Prosopis juliflora (Sw.) DC. & Algarobeira & Exótica & 03 & 1,86 \\
\hline \multicolumn{5}{|l|}{ MELIACEAE } \\
\hline Azadirachta indica A. Juss & Neem & Exótica & 12 & 7,45 \\
\hline \multicolumn{5}{|l|}{ MORACEAE } \\
\hline Ficus benjamina L. & Ficus & Exótica & 02 & 1,24 \\
\hline \multicolumn{5}{|l|}{ MYRTACEAE } \\
\hline Syzygium cumini (L.) Skeels & Azeitona-preta & Exótica & 05 & 3,11 \\
\hline \multicolumn{5}{|l|}{ NYCTAGINACEAE } \\
\hline Bougainvillea spectabilis Willd. & Primavera & $\begin{array}{l}\text { Nativa (Mata } \\
\text { Atlântica) }\end{array}$ & 03 & 1,86 \\
\hline \multicolumn{5}{|l|}{ RHAMNACEAE } \\
\hline Ziziphus joazeiro Mart. & Juazeiro & Nativa (Caatinga) & 03 & 1,86 \\
\hline
\end{tabular}

Na soma das praças, a maior representatividade foi da família Fabaceae, apresentando 7 espécies ( $n=7 ; 28 \%)$, seguida por Anacardiaceae $(n=2 ; 8 \%)$, Arecaceae $(n=2 ; 8 \%)$ e Bignoniaceae $(n=2 ; 8 \%)$, apresentando 2 espécies, e as demais famílias com apenas uma espécie (Figura 2).

Em relação à origem das espécies contabilizadas neste inventário, 102 espécies foram identificadas como exóticas (63,35\%) e 59 como nativas brasileiras (36,65\%). Observa-se que o percentual de espécies exóticas predomina em relação ao de espécies nativas, assim também como Souza et al. (2011) verificaram no diagnóstico das praças de Aracaju-SE, no qual a proporção maior era de espécies exóticas (58\%) e as nativas correspondiam à $42 \%$. 


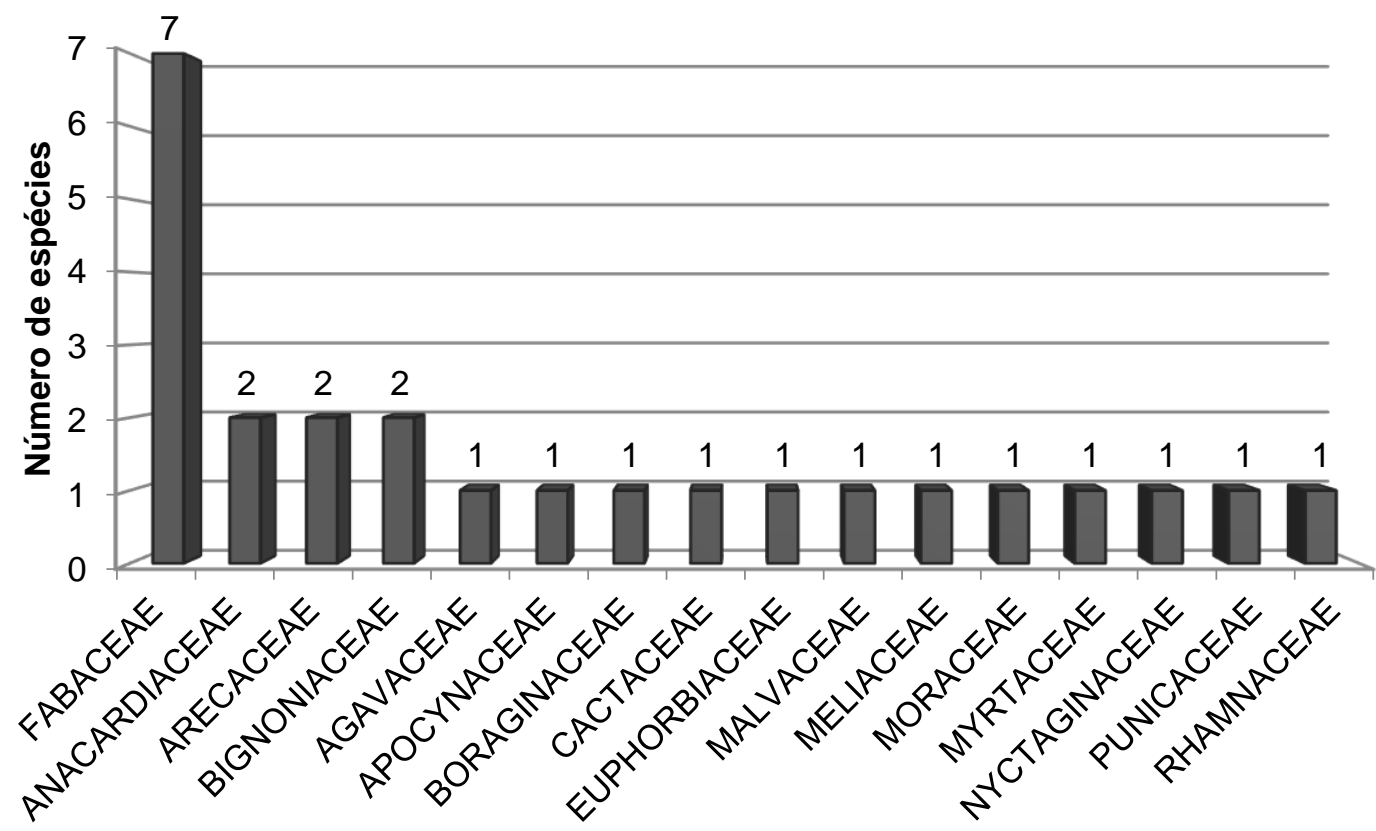

Famílias

Figura 2. Número total de espécies e suas respectivas famílias botânicas da Praça da Amizade e Frei Damião

Figure 2. Total number of species and their respective botanical families at Amizade and Frei Damião squares

A existência de uma maior quantidade de espécies exóticas em relação as nativas pode ser explicada pela prática frequente de uso dessas espécies, o que promove a desvalorização da flora local. De acordo com a SMAS (2013), deve-se priorizar espécies nativas e espécies típicas da fitogeografia de cada cidade na arborização urbana, devido elas auxiliarem no equilíbrio biológico, manutenção e recuperação da fitofisionomia da paisagem. No entanto, é muito comum encontrar um elevado percentual de espécies exóticas em grande parte das cidades brasileiras, geralmente maior que 70\% (BIONDI; LIMA NETO, 2011).

No diagnóstico quantitativo, entre as espécies nativas brasileiras existentes nas duas praças, 19 (11,81\%) são da espécie Tabebuia aurea, 13 (8,08\%) da espécie Libidibia ferrea e 8 $(4,97 \%)$ da espécie Enterolobium contortisiliquum. As espécies Ziziphus joazeiro ( $n=6 ; 3,73 \%)$ e Jatropha gossypiifolia $(n=6 ; 3,73 \%)$ apresentaram 6 indivíduos, $3(1,86 \%)$ da Bougainvillea spectabilis e com 1 indivíduo (0,62\%) as espécies Senna spectabilis, Melocactus zehntneri, Handroanthus sp. e Erythrina velutina.

Dentre as espécies exóticas que foram identificadas, na soma das praças a que apresentou a maior quantidade foi Azadirachta indica, indicando 38 indivíduos (23,6\%), seguida de Nerium oleander com 16 indivíduos (9,94\%), Agave americana com 10 indivíduos (6,21\%), Delonix regia com 7 indivíduos (4,35\%), Syzygium cumini com 5 indivíduos (3,11\%), Prosopis juliflora, Mangifera indica, Ficus benjamina, ambas com 5 indivíduos (3,11\%), Spondias purpurea 
e Cordia dichotoma com 3 indivíduos (1,86\%), Punica granatum, Palmeira não identificada, Hibiscus rosa-sinensis e Cocos nucifera com 1 indivíduo (0,62\%) (Figura 3 e 4).

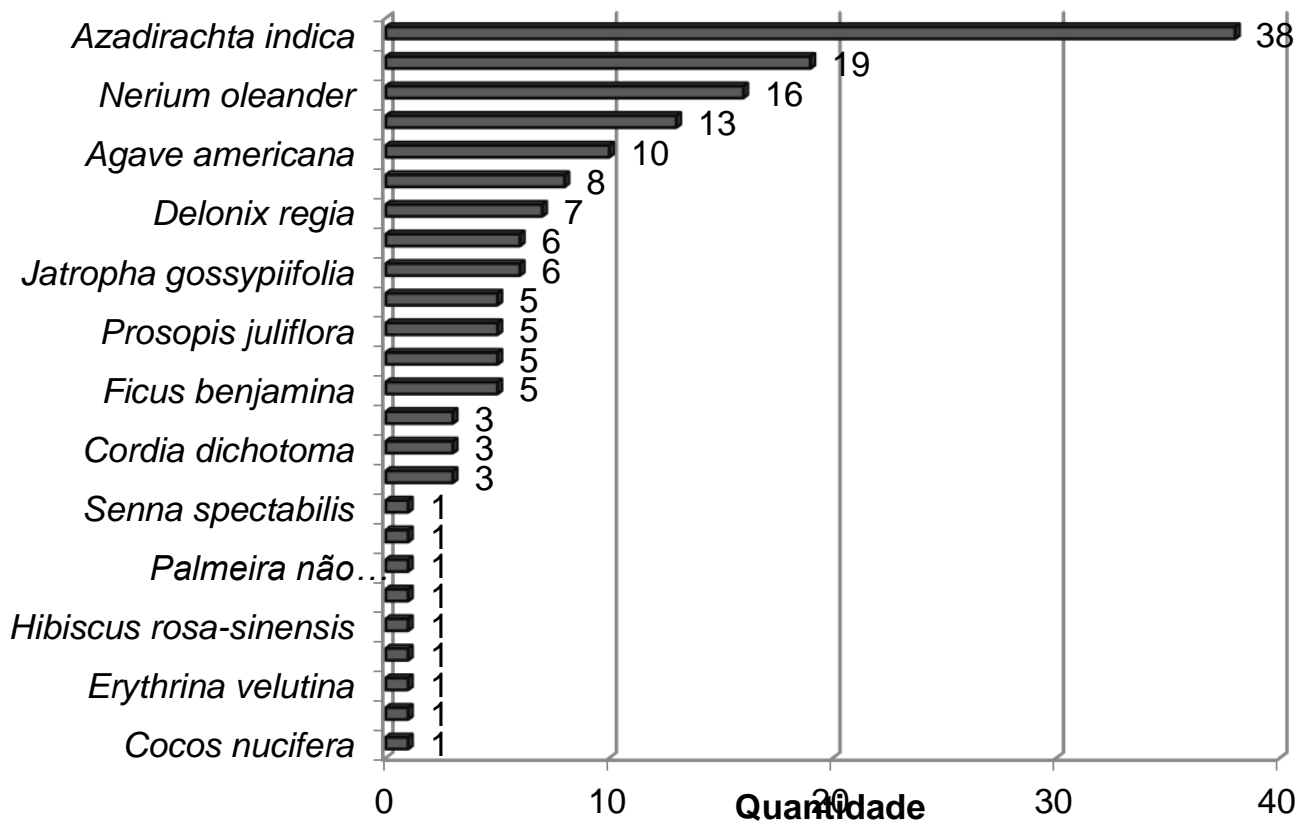

Figura 3. Soma do número de indivíduos encontrados na Praça da Amizade e Praça Frei Damião, Bairro José e Maria, Petrolina-PE

Figure 3. Sum of number of individuals found at Amizade and Frei Damião squares, José and Maria neighborhood, Petrolina-PE

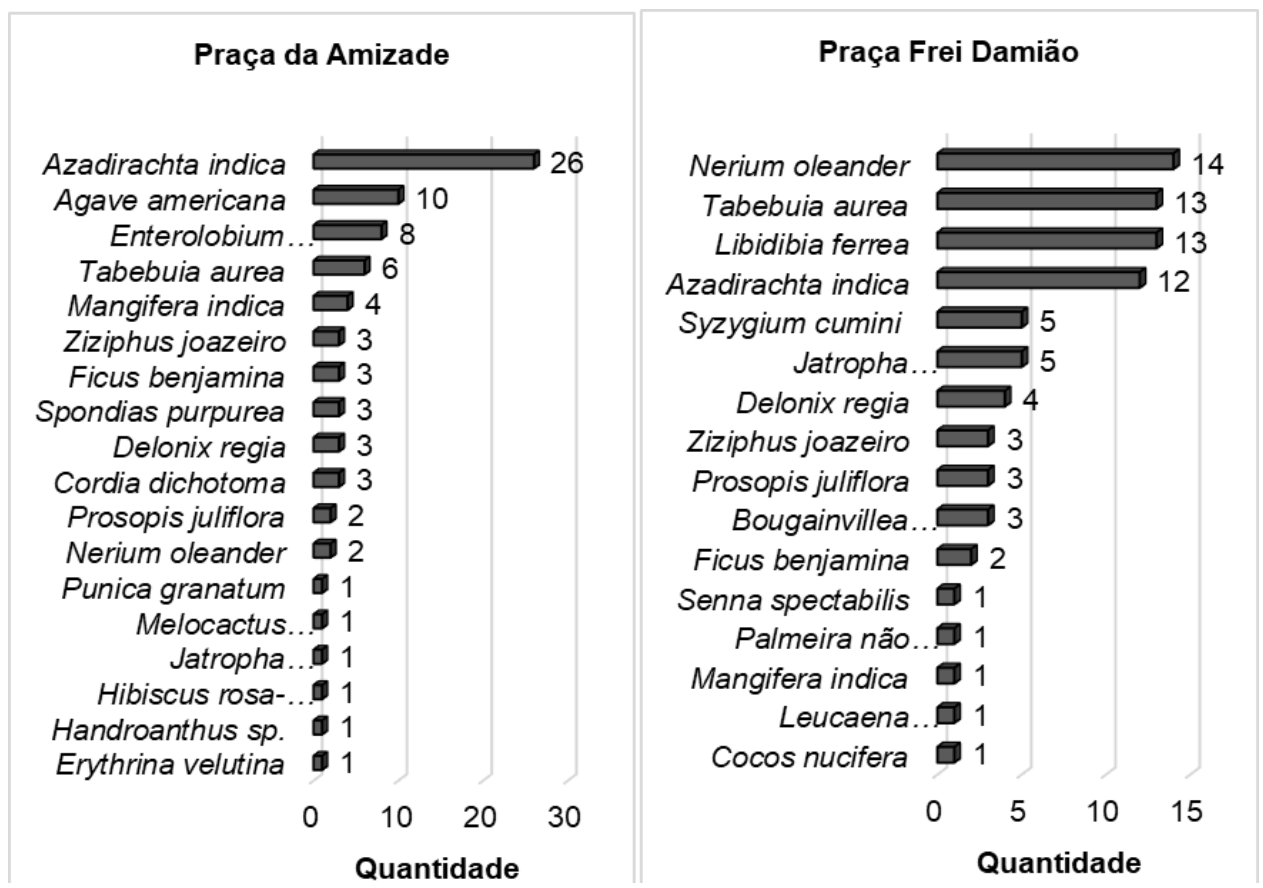

Figura 4. Número de indivíduos encontrados na Praça da Amizade e Praça Frei Damião, Bairro José e Maria, Petrolina-PE

Figure 4. Number of individuals found at Amizade Square and Frei Damião Square, José e Maria neighborhood, Petrolina-PE 
Grey e Deneke (1986) recomendam que cada espécie não deve ultrapassar 10 a 15\% do total de indivíduos da população arbórea, considerando que a predominância de apenas uma espécie ou grupo de espécies pode gerar riscos fitossanitários às plantas. No entanto, foi observado nesta pesquisa que Azadirachta indica apresentou um percentual bem maior do que o recomendado, correspondendo a $23,6 \%$ do total dos indivíduos observados.

$\mathrm{O}$ alto índice de $A$. indica encontrado nesse diagnóstico mostra que a introdução de espécies exóticas aleatoriamente provoca uma desvalorização da flora local (Figura 5).

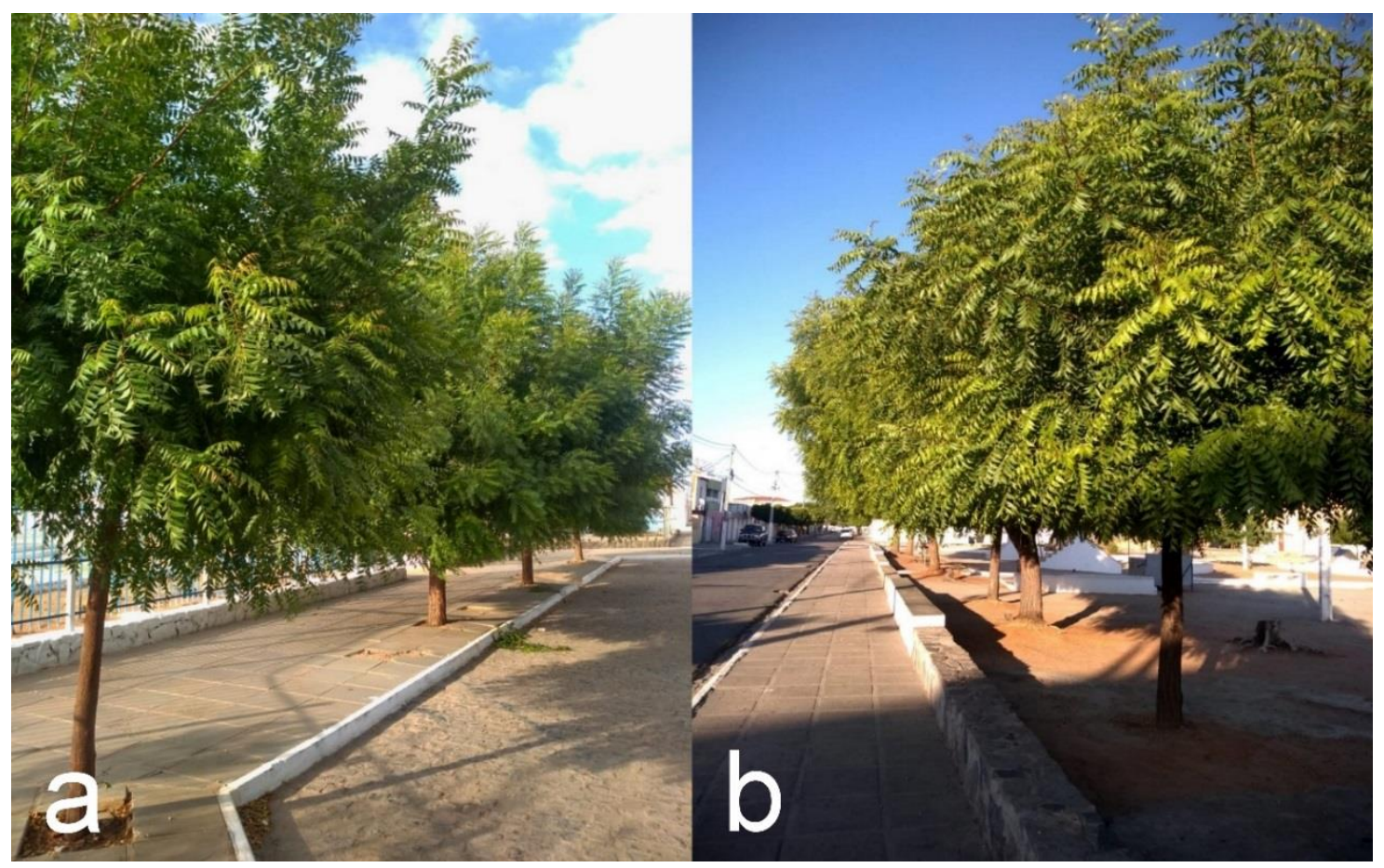

Fonte: Autores (2019)

Figura 5. Indivíduos de Azadirachta indica encontrados na (a) Praça da Amizade e (b) Praça Frei Damião Figure 5. Azadirachta indica individuals found in (a) Amizade Square and (b) Frei Damião Square

A ausência de conhecimento das potencialidades das espécies nativas, sobretudo da Caatinga, faz com que essas espécies sejam frequentemente substituídas por espécies exóticas na arborização urbana, promovendo uma descaracterização da flora nativa, além de outros problemas ambientais. O rápido crescimento de $A$. indica, o qual promove uma rápida formação de copa e, consequentemente, um rápido sombreamento dos ambientes, pode ser um dos motivos de sua introdução na arborização dessas praças, como ocorre em muitas cidades brasileiras. Dessa forma, é essencial a aplicação de um plano de arborização, buscando uma interação com a comunidade com projetos ambientais voltados para a conservação e valorização da flora nativa, pois esses espaços públicos (praças) são fundamentais para o desenvolvimento de atividades educativas, a exemplo da educação ambiental. 
O percentual elevado de uma mesma espécie, acima do limite recomendado (15\%), corrobora com outras pesquisas, tal como a de Crispim et al. (2014), que constataram também uma elevada frequência de espécies exóticas na arborização do centro da cidade de PombalPB, dentre elas a Azadirachta indica, que apresentou 42,1\% de frequência. Já Morais e Machado (2014) ressaltaram que a espécie $A$. indica se destacou no município de Timon, no Maranhão, com a maior representatividade, expressando 18,84\% ou 437 indivíduos. Em outro estudo, Zea et al. (2015) também verificaram um percentual elevado de $A$. indica, sendo um total de 864 indivíduos, o que representa 69,2\% dos indivíduos inventariados em Santa Helena, Paraíba.

Foi constatado também uma elevada presença de $A$. indica com 75,16\% de ocorrência nos municípios de Beberibe e Cascavel, no Ceará (EDSON-CHAVES et al., 2019). Brito et al. (2012) também constataram nas praças públicas do município de Bom Jesus-PI, um alto número de espécies exóticas, tendo como destaque a $A$. indica, que apresentou uma abundância de $29 \%$. Esses autores declaram ainda que a ausência de um planejamento da arborização urbana ou até mesmo a dificuldade para se obter mudas de espécies da flora regional, o que explica o fato da utilização de espécies exóticas em maior quantidade.

Souza (2017), em um estudo realizado no Parque Municipal Josefa Coelho, Petrolina$\mathrm{PE}$, também verificou uma elevada presença de Azadirachta indica, no qual a espécie apresentou um elevado número de indivíduos $(n=126 ; 16,64 \%)$, com a maioria das espécies $(n=374$; 49,41\%) de caráter exótico. O levantamento realizado no Parque Municipal Josefa Coelho, assim como o da Praça da Amizade e Frei Damião evidenciam que essa espécie vem ocupando grande espaço na arborização urbana da cidade de Petrolina, e esses dados mostram que as espécies exóticas, em particular $A$. indica, podem se tornar cada vez mais predominantes em relação as nativas e futuramente provocar problemas ecológicos e de valorização da flora local.

Azadirachta indica é uma árvore de origem asiática, sendo essa espécie inserida no Brasil no ano de 1986 com o objetivo de analisar a ação inseticida dessa planta (MARTINEZ, 2002). Na arborização urbana, $A$. indica é bastante difundida, sendo empregada no paisagismo de ruas, canteiros centrais de avenidas, praças, chácaras, dentre outros ambientes, e segundo Lundgren, Silva, Almeida (2013), é uma espécie que tolera muito bem constantes podas, até mesmo podas radicais. Apesar de apresentar um crescimento rápido e um agradável sombreamento, poderá colaborar para transformações ecológicas significativas no ambiente (VALE et al., 2011).

Silva (2012) enfatiza que não se deve colocar uma grande quantidade de uma mesma espécie num mesmo local, pela questão estética como também pela fitossanitária, uma vez que o local se torna não muito atraente e/ou harmonioso para a apreciação. De acordo com Alencar et al. (2014), a inserção de indivíduos de uma mesma espécie em grande quantidade na arborização urbana é resultante da ausência de um planejamento no qual os órgãos públicos 
não se preocupam com esse setor, facilitando a introdução de indivíduos pela população sem nenhum conhecimento técnico, mas, somente por influência de terceiros.

As espécies, Cocos nucifera, Erythrina velutina, Handroanthus sp., Hibiscus rosasinensis, Leucaena leucocephala, Melocactus zehntneri, Punica granatum, Senna spectabilis e uma palmeira não identificada apresentaram apenas um indivíduo, o que corresponde à 0,62\% cada um. Segundo Martins et al. (2014), esse fato pode ser um indício de que a arborização tenha sido realizada sem qualquer tipo de planejamento, aleatoriamente, ou até mesmo executada pela população.

\section{CONCLUSÕES}

A partir dos resultados encontrados, foi possível identificar uma predominância de espécies exóticas, particularmente Azadirachta indica, que apresentou um alto percentual e esse resultado é justificado pela introdução constante dessa espécie nos ambientes urbanos, que poderá, com o tempo, causar danos, como por exemplo alterações ecológicas, como também a desvalorização da flora local. É recomendado a utilização de espécies nativas, principalmente da Caatinga na arborização urbana, a fim de valorizar e preservar essas espécies e não descaracterizar a vegetação da região.

\section{REFERÊNCIAS}

AlenCAR, L. S. A.; SOUTO, P. C.; MOREIRA, F. T. A.; SOUTO, J. S.; BORGES, C. H. A. Inventário quali-quantitativo da arborização urbana em São João do Rio do Peixe - PB. Agropecuária Científica no Semiárido, Campina Grande, v. 10, n. 2, p. 117-124, 2014.

BASSO, J. M.; CORRÊA, R. S. Arborização urbana e qualificação da paisagem. Paisagem e Ambiente, São Paulo, v. 1, n. 34, p. 129-148, 2014.

BENATTI, D. P.; TONELLO, K. C.; ADRIANO JÚNIOR, F. C.; SILVA, J. M. S.; OLIVEIRA, I. R.; ROLIM, E. N.; FERRAZ, D. L. Inventário arbóreo urbano do município de Salto de Pirapora, SP. Revista Árvore, Viçosa, v. 36, n. 5, p. 887-894, 2012.

BIONDI, D.; LIMA NETO, E. M. Pesquisas em arborização de ruas. Curitiba: O Autor, 2011. $150 p$.

BRITO, D. R. S.; RAABE, J.; SOUSA, W. C.; MELO, R. R.; PEDROSA, T. D. Diagnóstico da arborização das praças pública no município de Bom Jesus, Piauí. Scientia Plena, Aracaju, v. 8, n. 4, p. 01-06, 2012. 
CRISPIM, D. L.; SILVA, M. A.; CHAVESS, A. D. C. G.; ALMEIDA, R. R. P.; FREITAS, A. J. F. Diagnóstico da arborização urbana do centro da cidade de Pombal-PB. Revista Verde de Agroecologia e Desenvolvimento Sustentável, Campina Grande, v. 9, n. 1, p. 191-196, 2014.

EDSON-CHAVES, B.; DANTAS, A. G. B.; LIMA, N. S.; PANTOJA, L. D. M.; MENDES, R. M. de S. Avaliação qualiquantitativa da arborização da sede dos municípios de Beberibe e Cascavel, Ceará, Brasil. Ciência Florestal, Santa Maria, v. 29, n. 1, p. 403-416, 2019.

GREY, G. W., DENEKE, F. J. Urban forestry. New York, John Wiley \& Sons, 1986. 279p.

LUNDGREN, W. J. C.; SILVA, L. F.; ALMEIDA, A. Q. Influência das espécies exóticas arbóreas urbanas na área de cobertura da cidade de Serra Talhada - PE. Revista da Sociedade Brasileira de Arborização Urbana, Piracicaba, v. 8, n. 3, p. 96-107, 2013.

MARTINEZ, S. S. O nim - Azadirachta indica: natureza, usos múltiplos, produção. Londrina: IAPAR, 2002. 142p.

MARTINS, L. C.; NUNES, A. L.; NUNES, A. M.; BRAGA, H. S. Análise comparativa da arborização urbana de três cidades da região do alto São Francisco/ Minas Gerais. Revista Agrogeoambiental, Pouso Alegre, v. 6 n. 2, p. 31-42, 2014.

MORAIS, L. A.; MACHADO, R. R. B. A arborização urbana do município de Timon/MA: inventário, diversidade e diagnóstico quali-quantitativo. Revista da Sociedade Brasileira de Arborização Urbana, Piracicaba, v. 9, n. 4, p 80-98, 2014.

NOWAK, D. J. Assessing urban forest structure: summary and conclusions. Arboriculture \& Urban Forestry, Champaing, v. 34, n. 6, p. 391-392, 2008.

OLIVEIRA, A. S.; SANCHES, L.; DE MUSIS, C. R.; NOGUEIRA, M. C. J. A. Benefícios da arborização em praças urbanas - o caso de Cuiabá/MT. Revista Eletrônica em Gestão, Educação e Tecnologia Ambiental, Santa Maria, v. 9, n. 9, p. 1900-1915, 2013.

PINHEIRO, C. R.; SOUZA, D. D. A importância da arborização nas cidades e sua influência no microclima. Revista Gestão e Sustentabilidade Ambiental, Florianópolis, v. 6, n. 1, p. 67-82, 2017.

SANTOS, C. Z. A.; FERREIRA, R. A.; SANTOS, L. R. C.; SANTOS, L. I.; GRAÇA, D. A. S.; GOMES, S. H.; PORTO NETO, W. B.; CORREIA, T. S.; BOSCHESE, A, C. B. Composição florística de 25 vias públicas de Aracaju - SE. Revista da Sociedade Brasileira de Arborização Urbana, Piracicaba, v. 6, n. 2, p. 125-144, 2011.

SILVA, R. N. Caracterização e análise quali-quantitativa da arborização em praças da área central da cidade de Arapiraca, AL. Revista da Sociedade Brasileira de Arborização Urbana, Piracicaba, v. 7, n. 2, p. 102-115, 2012.

SMAS. Secretaria de Meio Ambiente e Sustentabilidade. Manual de arborização: orientações e procedimentos técnicos básicos para a implantação e manutenção da arborização da cidade do Recife. 1. ed. - Recife: [s.n.], 2013. 71p.

SOUZA, A. L.; FERREIRA, R. A.; MELLO, A. A.; PLÁCIDO; D. R.; SANTOS, C. Z. A.; GRAÇA, D. A. S.; ALMEIDA JÚNIOR, P. P.; BARRETTO, S. S. B.; DANTAS, J. D. M.; PAULA, J. W. A.; 
SILVA, T. L.; GOMES, L. P. S. Diagnóstico quantitativo e qualitativo da arborização das praças de Aracaju, SE. Revista Árvore, Viçosa, v. 35, n. 6, p. 1253-1263, 2011.

SOUZA, D.D. Análise florística do componente arbóreo do Parque Municipal Josepha Coelho, Petrolina - PE. Revista da Sociedade Brasileira de Arborização Urbana, Piracicaba, v. 12, n. 4, p.42-52, 2017.

VALE, N. F. L.; SOUSA, G. S.; MATA, M. F.; BRAGA, P. E. T. Inventário da arborização do parque da cidade do município de Sobral, Ceará. Revista da Sociedade Brasileira de Arborização Urbana, Piracicaba, v. 6, n. 4, p. 145-157, 2011.

ZEA, C. J. D.; BARROSO, R. F.; SOUTO, P. C.; SOUTO J. S. Levantamento e diversidade da arborização urbana de Santa Helena, no semiárido da Paraíba. Agropecuária Científica no Semiárido, Campina Grande, v. 11, n. 4, p. 54-62, 2015. 